Article

\title{
THz Fingerprints of Cement-Based Materials
}

\author{
Jorge S. Dolado ${ }^{1,2,3, * \mathbb{C}}$, Guido Goracci ${ }^{1}$, Eduardo Duque ${ }^{2} \mathbb{D}$, Pavel Martauz ${ }^{4}$, Yibing Zuo ${ }^{3,5}$ \\ and Guang $\mathrm{Ye}^{3}$ (iD) \\ 1 Centro de Física de Materiales, CSIC-UPV/EHU, Paseo Manuel de Lardizabal 5, \\ 20018 Donostia/San Sebastián, Spain; Guido_goracci@ehu.eus \\ 2 Donostia International Physics Center (DIPC), Paseo Manuel de Lardizabal 4, 20018 Donostia/San Sebastián, \\ Spain; eduardo.duque@ehu.eus \\ 3 Microlab, Section Materials and Environment, Faculty of Civil Engineering and Geosciences, \\ Delft University of Technology (TU DELFT), Stevinweg 1, 2628 CN Delft, The Netherlands; \\ Zuo@tudelf.nl (Y.Z.); G.Ye@tudelft.nl (G.Y.) \\ 4 Povazska Cementaren a.s., Ladce, 01863 Ladce, Slovakia; martauz.p@pcla.sk \\ 5 Hubei Key Lab of Control Structures, Huazhong University of Science and Technology, No. 28, Nanli Road, \\ Hong-shan District, Wuhan 430068, China \\ * Correspondence: Jorge_dolado002@ehu.eus
}

Received: 26 August 2020; Accepted: 14 September 2020; Published: 21 September 2020

\begin{abstract}
To find materials with an appropriate response to $\mathrm{THz}$ radiation is key for the incoming $\mathrm{THz}$ technology revolution. Unfortunately, this region of the electromagnetic spectra remains largely unexplored in most materials. The present work aims at unveiling the most significant $\mathrm{THz}$ fingerprints of cement-based materials. To this end transmission experiments have been carried out over Ordinary Portland Cement (OPC) and geopolymer (GEO) binder cement pastes in combination with atomistic simulations. These simulations have calculated for the first time, the dielectric response of C-S-H and $\mathrm{N}-\mathrm{A}-\mathrm{S}-\mathrm{H}$ gels, the most important hydration products of OPC and GEO cement pastes respectively. Interestingly both the experiments and simulations reveal that both varieties of cement pastes exhibit three main characteristic peaks at frequencies around $\sim 0.6 \mathrm{THz}, \sim 1.05 \mathrm{THz}$ and $\sim 1.35 \mathrm{THz}$, whose origin is governed by the complex dynamic of their water content, and two extra signals at $\sim 1.95 \mathrm{THz}$ and $\sim 2.75 \mathrm{THz}$ which are likely related to modes involving floppy parts of the dried skeleton.
\end{abstract}

Keywords: THz characterization; atomistic modelling; cementitious structure

\section{Introduction}

Lying at the meeting point of electronic and photonic technologies, the terahertz (THz) region of the electromagnetic spectrum (frequencies from $10^{11}$ to $10^{13} \mathrm{~Hz}$ ) has lately attracted significant interest in materials science, communication and biomedical engineering [1]. A key challenge for the $\mathrm{THz}$ technology is to find materials with an appropriate response to the $\mathrm{THz}$ radiation, as most natural materials demonstrate weak wave-matter interaction at terahertz frequencies. Many fanciful $\mathrm{THz}$ devices have been proposed in the state of the art based on metamaterials (engineered subwavelength resonant metallic inclusions on dielectric spacers) for enhancing the response of materials at the $\mathrm{THz}$ region. These solutions are indeed a natural extension to the photonic metamaterials proposed in other electromagnetic spectrum frequencies, like the visible [2,3], Infrared (IR) [4,5], millimeter [6,7] and microwave regime $[8,9]$.

Complementary to the previous solutions, it is highly desirable to find materials with an intrinsic reasonable response within the $\mathrm{THz}$ region. In this sense, ubiquitous and cheap materials like cementitious materials deserve due attention. In fact, the main hydration products of Ordinary Portland Cements (OPC) and geopolymer (GEO) binders, the C-S-H and N-A-S-H gels respectively, 
contain many structural features which seem to favor the response to the $\mathrm{THz}$ radiation: On the one hand, the C-S-H and N-A-S-H gels are glassy and amorphous. In fact, the structure of C-S-H and N-A-S-H gels resemble distorted tobemorite clays and defective sodalite zeolites respectively, as numerous experiments [10-15] and atomistic models [16-20] have verified. In that sense, and though the underlying reason is still under debate, glassy and amorphous materials are known to host an overpopulation of vibrational states at the $\mathrm{THz}$ frequencies (the so-called Boson Peaks (BP)) [21-23]. Interestingly, recent atomistic simulations have predicted the possible existence of a BP in the C-S-H gel [24], though no experimental proof exists for the time being. In the case of N-A-S-H structures neither experiments nor simulations have paid attention to this interesting aspect. On the one hand, both C-S-H and N-A-S-H gels contain plenty of water molecules (either in the $\mathrm{H}_{2} \mathrm{O}$ or in the $\mathrm{OH}^{-}$form) which strongly interact with light due to their intrinsic electric dipole. In fact, the dielectric loss spectra of bulk water at room temperature exhibits a dominating peak at $0.02 \mathrm{THz}$ (usually ascribed to the $\alpha$-relaxation) that is flanked by two additional faster processes whose characteristic frequencies lie around 0.3-0.9 $\mathrm{THz}$ and 1.3-1.9 $\mathrm{THz}$ [25].

Unfortunately, the dielectric response of cement-based materials has not been sufficiently studied. To the best of our knowledge, only a few works have been published to date [26-29], studying the dynamic of water by broad band dielectric (BDS) spectroscopy at much lower frequencies $\left(10^{-2}\right.$ to $10^{6} \mathrm{~Hz}$ ). In this scenario, the present paper aims to report for the first time the state of the art, the experimental and computational dielectric response of cement-based materials to the THz radiation. To this end, THz transmission experiments have been carried out over cement pastes of OPC and Fly Ash (FA) GEO binders. In addition, atomistic simulations have been performed to evaluate the dielectric function of the most important ingredients of OPC and GEO cement pastes, the C-S-H and N-A-S-H gels.

\section{Materials and Methods}

\subsection{Sample Preparation}

\subsubsection{OPC Cement Pastes}

Starting powders of OPC (CEM I-42.5R) (Povazska Cementaren a.s., Ladge, Slovakia) were mixed with distilled water (Sigma Aldrich, St. Louis, MO, USA) in a water-to-cement ratio of 0.4 by weight. Each specimen was cast in a cylindrical mold $(\varnothing 38 \times \mathrm{H} 15 \mathrm{~mm})$ and sealed. After $24 \mathrm{~h}$, the sample discs were moved to a hermetically closed desiccator with $100 \% \mathrm{RH}$ and kept at $20{ }^{\circ} \mathrm{C}$ for 28 days.

\subsubsection{GEO Cement Pastes}

Fly ash-based geopolymer cement pastes were used in the experiments. Low calcium fly ash, Class F according to ASTM C 618, from The Netherlands, was used. The chemical composition of the fly ash is given in Table 1 . It is noted that the main constituents of the fly ash are $\mathrm{SiO}_{2}$ and $\mathrm{Al}_{2} \mathrm{O}_{3}$. Quartz $\left(\mathrm{SiO}_{2}\right)$ and mullite $\left(3 \mathrm{Al}_{2} \mathrm{O}_{3} 2 \mathrm{SiO}_{2}\right)$ are the main crystalline compounds in the fly ash (Figure 1). The amorphous content of the fly ash, determined by the chemical dissolution treatment (EN 196, Part 2), is 69\%. The density and mean particle size of the fly ash is $2.34 \mathrm{~g} / \mathrm{m}^{3}$ and $21.46 \mu \mathrm{m}$, respectively. $\mathrm{NaOH}$ activator was prepared by sodium hydroxide (analytical grade $>98 \%$ ) and distilled water. Then fly ash and $\mathrm{NaOH}$ activator were mixed in a commercial Hobart mixer with two minutes low-speed (140 r/min) mixing, followed by two minutes high-speed $(285 \mathrm{r} / \mathrm{min})$ mixing. Subsequently the freshly prepared paste was cast into commercial cylinder polyethylene jars $(\mathrm{d}=35 \mathrm{~mm}$ and $\mathrm{h}=70 \mathrm{~mm})$ and vibrated for $30 \mathrm{~s}$ on a vibrating table. The water to fly ash mass ratio was 0.35 . The samples were cured in a water bath at elevated temperatures $\left(40 / 60^{\circ} \mathrm{C}\right)$ until test age (28 days). 
Table 1. Chemical composition of fly ash.

\begin{tabular}{cccccccccc}
\hline \multicolumn{10}{c}{ Oxide (wt.\%) } \\
\hline & $\mathrm{SiO}_{2}$ & $\mathrm{Al}_{2} \mathrm{O}_{3}$ & $\mathrm{CaO}$ & $\mathbf{M g O}$ & $\mathrm{Fe}_{\mathbf{2}} \mathrm{O}_{3}$ & $\mathrm{SO}_{3}$ & $\mathbf{K}_{\mathbf{2}} \mathbf{O}$ & $\mathrm{TiO}_{2}$ & Other \\
\hline Fly ash & 56.8 & 23.8 & 4.8 & 1.5 & 7.2 & 0.3 & 1.6 & 1.2 & 2.8 \\
\hline
\end{tabular}

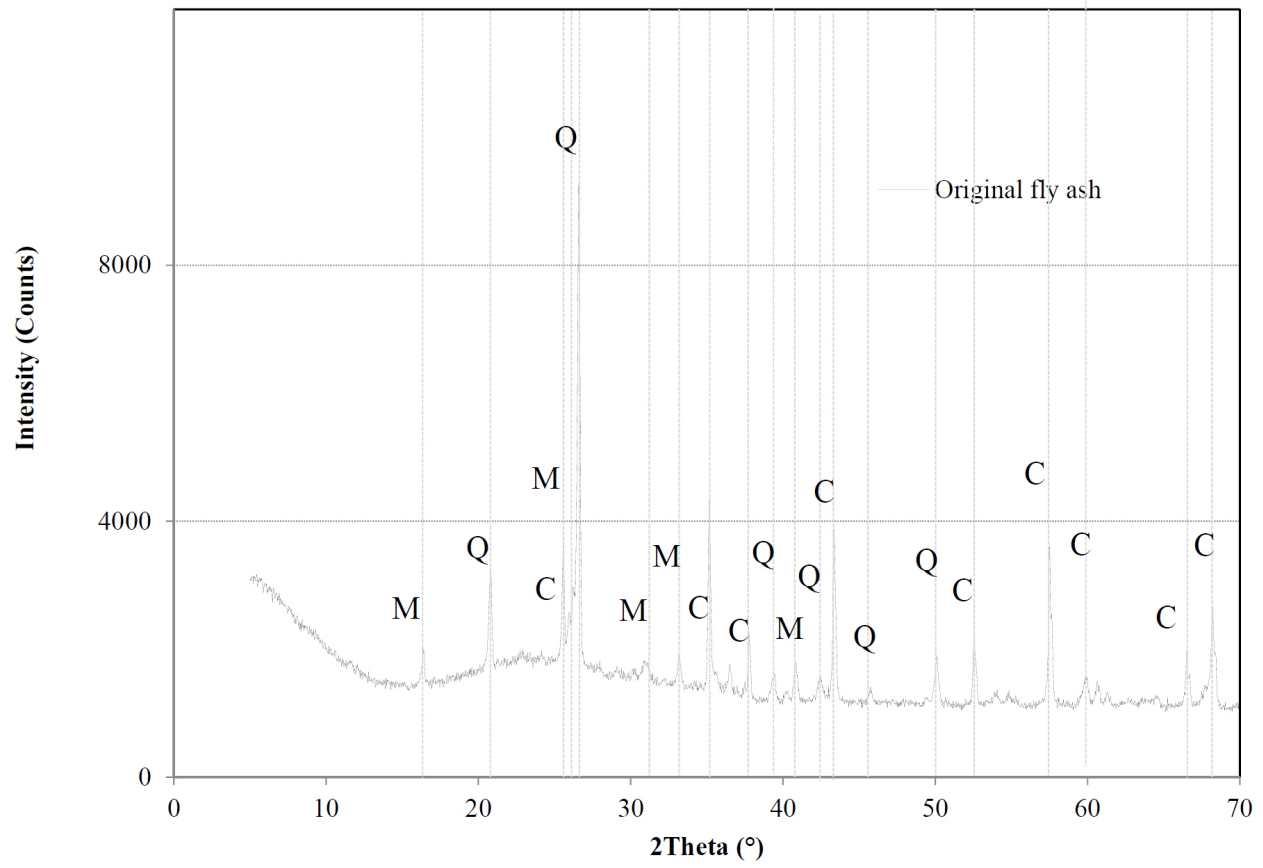

Figure 1. X-ray diffraction analysis of the fly ash, $\mathrm{Q}=$ quartz $\left(\mathrm{SiO}_{2}\right) ; \mathrm{M}=$ mullite $\left(\mathrm{Al}_{4.8} \mathrm{O}_{9.54} \mathrm{Si}_{1.2}\right)$ and $\mathrm{C}=$ Corundum $\left(\alpha-\mathrm{Al}_{2} \mathrm{O}_{3}\right)$.

\subsection{THz Measurements}

The time-domain THz transmission experiments were performed by using a TPS Spectra 3000 spectrometer (TeraView Ltd., Cambridge, UK). Samples were measured covering the spectral range 0.05 to $4 \mathrm{THz}$ at an instrument resolution of $\sim 0.035 \mathrm{THz}$. A special Teflon sample holder was prepared to investigate powder samples. The use of powder samples makes it impossible to determine with accuracy absolute intensities but avoids the structural changes that can potentially take place when preparing pellets. The size of the powders was below $50 \mu \mathrm{m}$ to minimize spurious frequency dependent scattering effects in the measured $\mathrm{THz}$ window. Each spectrum was collected as 1800 co-added time-domain spectra collected over a period of $1 \mathrm{~min}$.

\subsection{Atomistic Simulations}

\subsubsection{Starting Structures}

As stated in the Introduction, the key ingredients of OPC and geopolymer-based cement pastes are the C-S-H and N-A-S-H gels, respectively. To simulate the structure of C-S-H the procedure described by Qomi et al. [19], based on an improvement of the original procedure proposed by Pellenq et al. [16] has been employed. A schematic description of the employed protocol for constructing the C-S-H structure is displayed in Figure 2 (upper panel). As such, the structure of Tobermorite 14 (with $C / S=0.83$ ) is taken as the starting point, modifying its structure by firstly removing the water molecules. Afterwards some bridging silicate groups are also randomly removed to get the targeted $\mathrm{C} / \mathrm{S}$ ratio. Finally, to avoid charge unbalances and get the right water content, some Ca ions and water molecules are randomly added in inter-laminar space. The so obtained structure is finally equilibrated by performing energy minimization and Molecular Dynamic (MD) simulation with the Reax FF [30]. Complete details of 
the method can be found in Duque [31]. The present study limits the study to the calcium-to-silicon ratio (C/S) 1.67 case, as it is the typical vale found in OPC C-S-H gels. The constructed C-S-H model actually corresponds to a very large system (see Table 2 for the simulation cell parameters) whose exact stoichiometry is $(\mathrm{CaO})_{254}\left(\mathrm{SiO}_{2}\right)_{152}\left(\mathrm{H}_{2} \mathrm{O}\right)_{306}$.
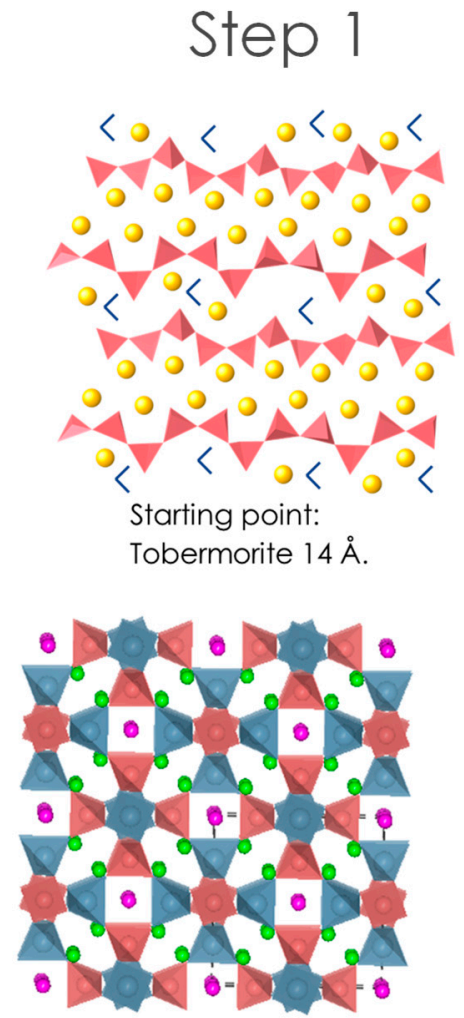

Starting point:

Sodalite

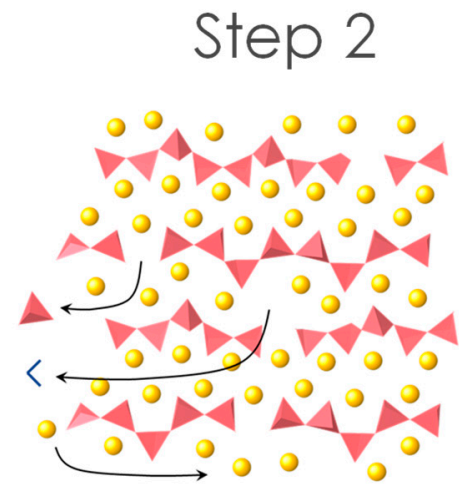

Remove all water and some bridging silicates. Add $\mathrm{Ca}^{2+}$

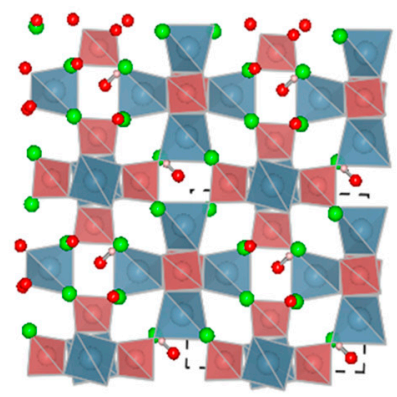

Replace $\mathrm{Cl}^{-}$by $\mathrm{OH}^{-}$

and relax with ReaxFF
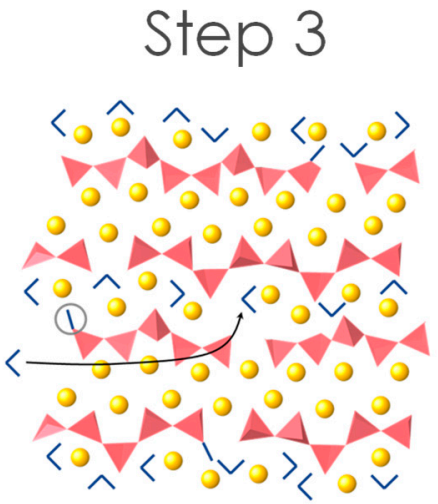

Reintroduce water. Chemical and structural relaxation with ReaxFF.

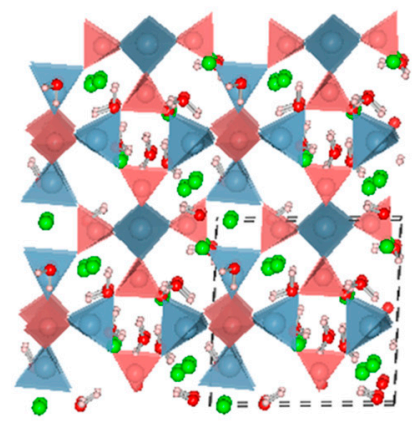

Introduce water molecules by GCMC and relax with ReaxFF

Figure 2. Sketch of the protocol for constructing the C-S-H model (upper panel) and N-A-S-H structures (bottom panel).

Table 2. Stoichiometry and lattice constants and angles of the studied C-S-H and N-AS-H structures.

\begin{tabular}{ccc}
\hline & C-S-H & N-A-S-H \\
\hline Composition & $(\mathrm{CaO})_{254}\left(\mathrm{SiO}_{2}\right)_{152}\left(\mathrm{H}_{2} \mathrm{O}\right)_{306}$ & $\left(\mathrm{Na}_{2} \mathrm{O}\right)_{4}\left(\mathrm{Al}_{2} \mathrm{O}_{3}\right)_{3}\left(\mathrm{SiO}_{2}\right)_{6}(\mathrm{OH})_{2}\left(\mathrm{H}_{2} \mathrm{O}\right)_{9}$ \\
\hline $\mathrm{a}(\AA)$ & 26.083000 & 9.483393 \\
\hline $\mathrm{b}(\AA)$ & 30.847000 & 9.11116 \\
\hline $\mathrm{c}(\AA)$ & 25.885000 & 9.040023 \\
\hline$\alpha\left(^{\circ}\right)$ & 90 & 92.536179 \\
\hline$\beta\left(^{\circ}\right)$ & 90 & 91.007071 \\
\hline$\gamma\left({ }^{\circ}\right)$ & 90 & 88.652042 \\
\hline
\end{tabular}

On the other hand, a N-A-S-H model has been constructed following a protocol akin to the one recently proposed by Lolli et al. [20], as schematically shown in Figure 2 (lower panel). In particular, the starting structure has been the experimental sodalite structure $\left(\mathrm{Na}_{8}\left[\mathrm{Al}_{6} \mathrm{Si}_{6} \mathrm{O}_{24}\right] \mathrm{Cl}_{2}\right)$ given by Hasan et al. [32] in which we have replaced the $\mathrm{Cl}$ atoms with hydroxide ions $\left(\mathrm{OH}^{-}\right)$. After relaxing the structure by using ReaxFF [30], we have applied a Gran Canonical Monte Carlo (GCMC) protocol to introduce water into its structure. To this end a chemical potential of $-0.082 \mathrm{eV}$ has been fixed. As a 
result, the final structure became $\left(\mathrm{Na}_{2} \mathrm{O}\right)_{4}\left(\mathrm{Al}_{2} \mathrm{O}_{3}\right)_{3}\left(\mathrm{SiO}_{2}\right)_{6}(\mathrm{OH})_{2} \cdot\left(\mathrm{H}_{2} \mathrm{O}\right)_{9}$. Finally, the structure has been relaxed again with ReaxFF, giving the lattice constants and angles disclosed in Table 2.

\subsubsection{Dielectric Response Simulations}

Computationally speaking, the relevance of this work is surely due to the new methodology disclosed for estimating the dielectric function of cement-based materials. While these sorts of simulations have been already employed in other materials like quartz [33], to the best of our knowledge this is the first time that the dielectric properties of cement-based materials have been simulated. In essence, the underlying idea is that the angular frequency $(\omega=2 \pi v)$ dependent dielectric function can be calculated in terms of the atomic vibrations (phonons) and more specifically in terms of the oscillator strength $\Omega$ as:

$$
\varepsilon_{i j}(\omega)=\varepsilon_{i j}(\infty)+\frac{4 \pi}{V} \sum_{m}^{\text {modes }} \frac{\Omega_{i j}^{m}}{\omega_{m}^{2}-\omega^{2}}
$$

where the oscillator strength tensor for each vibrational mode $m$ depends on the Born effective charges $\left(q^{B}\right)$ and the eingenvector $\left(e_{i j}\right)$ for that mode according to:

$$
\Omega_{\alpha \beta}=\left(\sum_{i}^{N} \frac{q_{i \alpha j}^{B} e_{i j}}{m_{i}^{1 / 2}}\right)\left(\sum_{i}^{N} \frac{q_{i \beta j}^{B} e_{i j}}{m_{i}^{1 / 2}}\right)
$$

As in GULP [34] the Born effective charges are not implemented for ReaxFF, these charges have been obtained through the non-reactive force field employed in [18]. To avoid the singularities of Equation (1) a small damping term $(\delta)$ of $0.15 \mathrm{THz}$ has been used (i.e., $\omega^{2} \rightarrow \omega(\omega+i \delta)$ ). For the sake of simplicity, only the diagonal values of the dielectric function matrix have been considered to estimate the values of the dielectric function; i.e., we have taken $\varepsilon(\omega)=\left(\varepsilon_{x x}(\omega)+\varepsilon_{y y}(\omega)+\varepsilon_{x x}(\omega)\right) / 3$ for the real $\left(\varepsilon_{1}\right)$ and imaginary part $\left(\varepsilon_{2}\right)$ of the dielectric function.

Finally, from the knowledge of the dielectric function, the complex refraction index $\left(n=n_{1}+i n_{2}\right)$ and the absorbance $(\alpha)$ can be obtained from Equations (3) and (4), respectively:

$$
\begin{gathered}
\varepsilon_{1}+i \varepsilon_{2}=\left(n_{1}+i n_{2}\right)^{2} \\
\alpha(\omega)=\frac{2 \omega n_{2}(\omega)}{c}
\end{gathered}
$$

\section{Results}

Figure 3 displays the experimental absorbance of the OPC cement pastes in the $\mathrm{THz}$ regime (Figure 3a) in comparison to the computational prediction of the response of C-S-H gel (Figure 3b). As is customary in the field, the absorbance has been divided by the square of the frequency to take out the normal $\sim v^{2}$ dependence of the vibrational density of the states and highlight the $\mathrm{THz}$ response. As absolute values cannot be comparable because cement pastes contain more phases than C-S-H (apart from the experimental problem of using powders, as explained in the Methods section), arbitrary units have been used to compare the spectra. The deconvolution of the experimental spectra has been performed by fitting the data with several gaussians over a $1 / v^{2}$ background. As shown in the Appendix A (Figures A1 and A2), at least five gaussians are required for an appropriated fitting of the experimental spectra. The positions of these five gaussians $\left(v_{n}\right)$ should be understood as the intrinsic THz fingerprints of OPC cement pastes. The values of these frequencies are collected in Table 3. The simulations also recognize several peaks $\left(v_{n}\right)$ that can be ascribed as intrinsic $\mathrm{THz}$ fingerprints of the C-S-H gel. These values are also reported in Table 3. Note that the experimental and computational frequencies are in good accord, exhibiting noticeable peaks at $\mathrm{v}_{1} \sim 0.60 \mathrm{THz}$ and $\mathrm{v}_{2} \sim 1.05 \mathrm{THz}$, and minor 
ones at $\mathrm{v}_{3} \sim 1.35 \mathrm{THz}, \mathrm{v}_{4} \sim 1.95 \mathrm{THz}$ and $\mathrm{v}_{5} \sim 2.75 \mathrm{THz}$. This last signal extracted from the deconvolution $\left(\mathrm{v}_{5} \sim 2.75 \mathrm{THz}\right)$ can be assigned to the two final bumps of the simulations at $2.35 \mathrm{THz}$ and $2.90 \mathrm{THz}$.
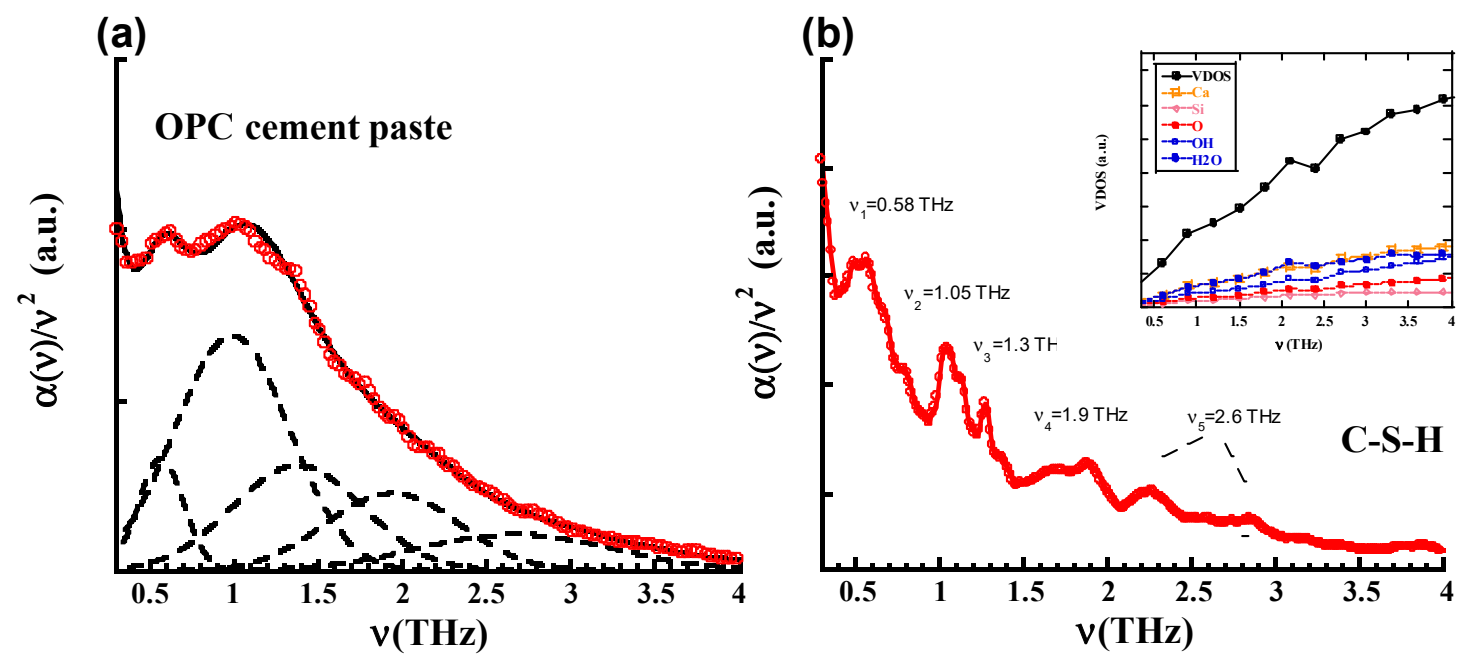

Figure 3. (a) Experimental absorbance of the Ordinary Portland Cements (OPC) cement paste, together with the deconvolution of the spectra. (b) Computational prediction of the absorbance for the C-S-H model. In the inset the Vibrational Density of States (VDOS) and their projections are displayed.

Table 3. Experimental THz frequencies of the main peaks detected in transmission experiments over OPC and geopolymer cement pastes along with the values predicted for C-S-H and N-A-S-H models by atomistic simulations. The uncertainties for the peaks of the fitting scheme have been estimated according to the method explained in Appendix A, while those of the simulations are below the used damping parameter $(0.15 \mathrm{THz})$.

\begin{tabular}{cccccc}
\hline & $\mathbf{v}_{\mathbf{1}} \mathbf{( T H z )}$ & $\mathbf{v}_{\mathbf{2}} \mathbf{( T H z )}$ & $\mathbf{v}_{\mathbf{3}} \mathbf{( T H z )}$ & $\mathbf{v}_{\mathbf{4}} \mathbf{( T H z )}$ & $\mathbf{v}_{\mathbf{5}} \mathbf{( T H z )}$ \\
\hline OPC (Exp) & $0.58 \pm 0.01$ & $1.0 \pm 0.01$ & $1.40 \pm 0.001$ & $1.95 \pm 0.001$ & $2.75 \pm 0.01$ \\
\hline C-S-H (Sim) & 0.58 & 1.05 & 1.30 & 1.90 & $2.30,2.85$ \\
\hline GEO (Exp) & $0.6 \pm 0.06$ & $1.0 \pm 0.05$ & $1.4 \pm 0.01$ & $1.95 \pm 0.05$ & $2.75 \pm 0.02$ \\
\hline N-A-S-H (Sim) & $0.5-0.8$ hump & 1.15 & 1.4 & 1.95 & 2.57 \\
\hline
\end{tabular}

The results for the GEO cement paste and the N-A-S-H structure are shown in Figure 4. Figure 4a shows the experimental absorbance together with the deconvolutions and Figure $4 \mathrm{~b}$ reports the predictions obtained from the atomistic simulations of the N-A-S-H model. In comparison to the case of OPCs, the convolution of the geopolymer spectra exhibits the same THz peaks $\left(\mathrm{v}_{1} \sim 0.60 \mathrm{THz}\right.$, $\mathrm{v}_{2} \sim 1.05 \mathrm{THz}, \mathrm{v}_{3} \sim 1.35 \mathrm{THz}, \mathrm{v}_{4} \sim 1.95 \mathrm{THz}$ and $\mathrm{v}_{5} \sim 2.75 \mathrm{THz}$.), though with a different relative intensity. Again, the simulations are able to capture reasonably well the positions of the peaks. The whole set of frequencies detected experimentally and computationally are collected in Table 3. It is worth noting, nevertheless, that the first peak appears as a diffuse hump in the simulations $(0.5-0.8 \mathrm{THz})$, while in the experiments it is only distinguishable from the background by the deconvolution of the spectra. This is in stark contrast to the case of the OPC paste and C-S-H gel, where this first peak was clearly visible. It is also noteworthy that according to the measurements the relevance of the second and third peaks seems to be inverted in the GEO cement pastes with respect to the OPC cement pastes. Now, the second peak $\left(\mathrm{v}_{2} \sim 1.05 \mathrm{THz}\right)$ seems to be much weaker than the third one $\left(\mathrm{v}_{3} \sim 1.4 \mathrm{THz}\right)$, while in the OPC cement paste the second one was the stronger one. This pattern is not reproduced in the simulations, where in both the C-S-H and N-A-S-H models, the signal at $\mathrm{v}_{3} \sim 1.4 \mathrm{THz}$ is the weakest one. Finally, the fourth $\left(\mathrm{v}_{4} \sim 1.95 \mathrm{THz}\right)$ and fifth peaks $\left(\mathrm{v}_{5} \sim 2.75 \mathrm{THz}\right)$ seem to match well with the results 
found previously in OPC and C-S-H gels. The simulations of N-A-S-H give a slightly better description for the position of these peaks in comparison to the C-S-H case.
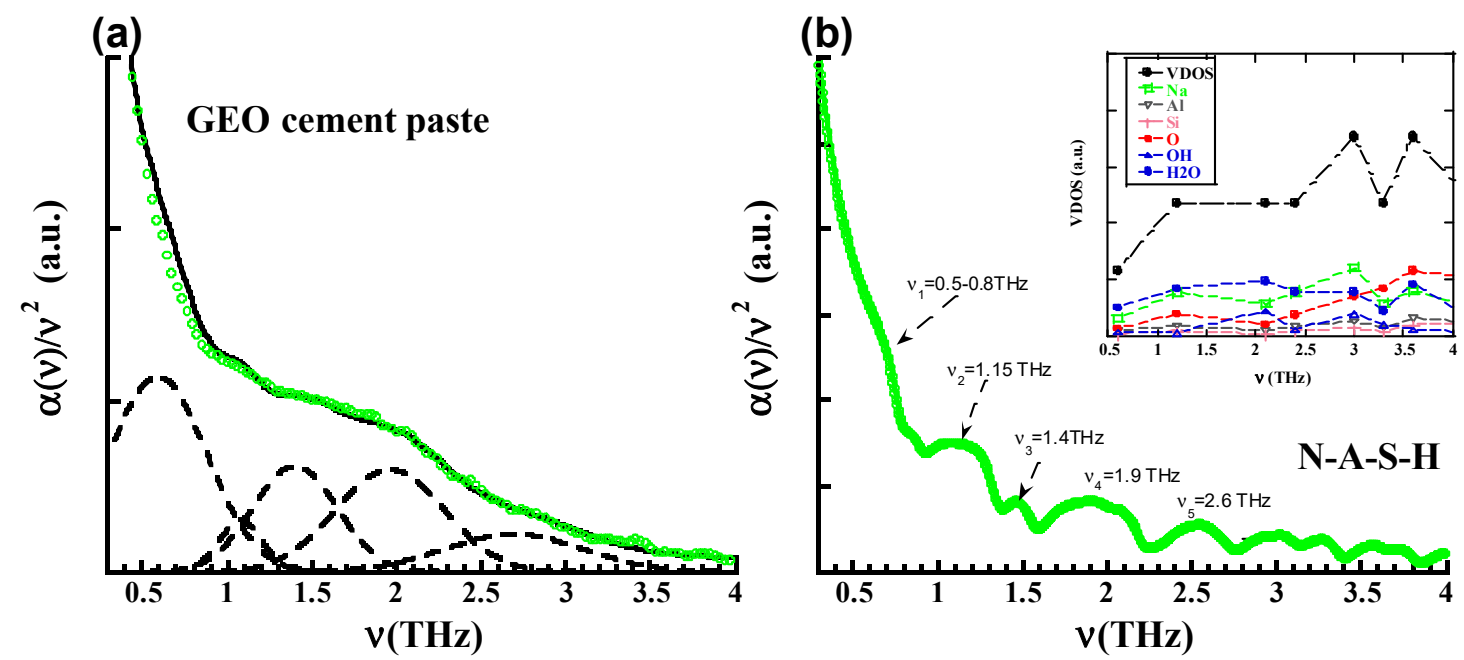

Figure 4. (a) Experimental absorbance of the geopolymer cement paste, together with the deconvolution of the spectra. (b) Computational prediction of the absorbance for the N-A-S-H model. In the inset the VDOS and their projections are displayed.

To shed light on the origin of these peaks, the Vibrational Density of States (VDOS) and their projections over the atoms/molecules involved have been calculated for the C-S-H and N-A-S-H models. The VDOS at a given frequency $v$ characterizes the number of phonons having a frequency in the range of $\mathrm{n}$ and $v+\mathrm{d} v$. It can be expressed in terms of the total number of modes $\mathrm{M}$ and the frequencies of the modes $v_{i}$ as

$$
g(v)=\sum_{i}^{M} \delta\left(v-v_{i}\right)
$$

The insets of Figures $3 \mathrm{~b}$ and $4 \mathrm{~b}$ show the VDOS for the C-S-H and N-A-S.H gel respectively. According to the VDOSs and their projections over the atoms, the low frequency region is clearly dominated by modes involving mainly $\mathrm{H}_{2} \mathrm{O}$ molecules (blue dots) and $\mathrm{Ca}$ atoms (orange open squares) in the case of C-S-H gel and $\mathrm{H}_{2} \mathrm{O}$ molecules (blue dots) and $\mathrm{Na}$ atoms (green open squares) in the case of N-A-S-H gel. While this dominant role of $\mathrm{H}_{2} \mathrm{O}$ molecules and $\mathrm{Ca}$ atoms persists in C-S-H gel along the shown $0.5-4 \mathrm{THz}$ region, beyond this point (though not shown) $\mathrm{OH}$ groups (open blue dots) and oxygen atoms (red dots) of the solid C-S-H skeleton start giving substantial contributions. In the case of the N-A-S-H gel, the modes involving the solid N-A-S-H skeleton start earlier ( $\sim 3 \mathrm{THz})$, as can be deduced by inspecting the projection over the oxygen atom (red dots).

\section{Discussion}

A simple picture emerges from the inspection of the VDOS and the $\mathrm{THz}$ dielectric response. While at high frequencies $(>2-3 \mathrm{THz})$ the observed and predicted low intensity bumps start having contributions coming from the solid skeleton, the five $\mathrm{THz}$ peaks observed in the OPC and GEO cement pastes correspond to low frequency water-related vibrations. Thus, it seems clear that the solution trapped in the nano/micro-pores of the cement pastes should have similar vibrational modes, giving rise to an additional contribution to the absorbance intensity. This fact can explain the discrepancies between the intensities measured over the cement pastes and the ones predicted by the simulations for the C-S-H and N-A-S-H gels. Moreover, the positions of the peaks (both measured and predicted) match extremely well with those found in previous studies on confined and hydration water. Very sharp peaks at $\sim 0.6 \mathrm{THz}$ have been found for instance in Molecular Dynamic simulations of supercooled 
water [35] or in THz transmission measurements over hydrated proteins [36]. Likewise, the second and third peaks at $\sim 1.0 \mathrm{THz}$ and $1.4 \mathrm{THz}$ found in our $\mathrm{TH}$ experiments and simulations agree well with the Boson peak of water, since this structural fingerprint has been found at $1.1 \mathrm{THz}$ in protein hydration water [36] and at $1.35 \mathrm{THz}$ in confined water [35,37]. In fact, neutron scattering experiments have recently observed a wide Boson peak at $\sim 1.35 \mathrm{THz}$ for water confined in the porous network of cement pastes [37]. In this sense, it is worth noting that the peaks detected by the $\mathrm{THz}$ experiments in OPC cement-based materials seem to emphasize more the signal coming from the "solvation water" $(1.1 \mathrm{THz})$ than the one from the "bulk-like" confined water $(1.35 \mathrm{THz})$. On the contrary, the bulk-like confined water appears as the dominant contribution in GEO matrices. Finally, modes at $\sim 1.95 \mathrm{THz}$ and $\sim 2.75 \mathrm{THz}$ have been previously identified by THz experiments in protein-solvent systems [36,38] and associated to internal side-chain fluctuations of the proteins indirectly connected to the hydration water dynamics. In an analogy to our case, these peaks might be related to modes involving floppy parts of the solid (dried) skeletons, where water molecules are also indirectly affected. In a separate paper we will provide further insight into this issue by studying the influence of the water content on the $\mathrm{THz}$ response of OPC and GEO matrices.

So far, this work reports for the first time the state-of-the-art $\mathrm{THz}$ measurements over cementitious materials, revealing that this technique can provide valuable structural information. In the range analyzed $(0.5-4 \mathrm{THz})$ five peaks have been found. The first three $\left(\mathrm{v}_{1} \sim 0.6 \mathrm{THz}, \mathrm{v}_{2} \sim 1.0 \mathrm{THz}\right.$ and $\mathrm{v}_{3} \sim 1.4 \mathrm{THz}$ ) are intrinsic fingerprints of the complex water dynamic present in cement-based materials, and the following two $\left(\mathrm{v}_{4} \sim 1.95 \mathrm{THz}\right.$ and $\left.\mathrm{v}_{5} \sim 2.75 \mathrm{THz}\right)$ surely relate to modes involving the solid (dried) skeleton. Moreover, it is also the first time that the dielectric properties of cement-based materials have been predicted by atomistic simulations. Considering the approximate nature of the force fields employed, the atomistic simulations have reproduced quite satisfactorily the experimental positions of these peaks. Future research on this topic should explore in greater detail the impact of the water content on the $\mathrm{THz}$ response of these materials and extend the scope to other binders like novel hybrid cements (H-CEM) [39], or well established calcium sulphoaluminates (C\$A) or calcium aluminates (CA).

Author Contributions: Conceptualization J.S.D. and G.G.; modelling, J.S.D. and E.D.; experimental validation, G.G., J.S.D., G.Y., P.M. and Y.Z.; writing-original draft preparation, J.S.D.; writing-review and editing, J.S.D., G.G., G.Y., E.D. and P.M. All authors have read and agreed to the published version of the manuscript.

Funding: This work is partially supported by the Gobierno Vasco-UPV/EHU project IT1246-19 and the Spanish Ministry of Science, Innovation and Universities projects PCI2019-103657 and RTI2018-098554-B-I00. Besides, the economic support from POVAZSKA and SKKC foundation is also acknowledged.

Acknowledgments: The computational services of DIPC and CFM are acknowledged.

Conflicts of Interest: The authors declare no conflict of interest.

\section{Appendix A}

In order to fit the $\mathrm{THz}$ spectra, the undertaken protocol has been the use of several gaussians over a $1 / v^{2}$ background. A systematic study in terms of the number of gaussians has been performed where the positions and width of the gausssians were freely optimized to fit the spectra. Figures A1 and A2 show respectively the deconvolution of the spectra of OPC and GEO cement pastes in terms of the number of gaussians $(\mathrm{N})$, covering the range from $\mathrm{N}=2$ to $\mathrm{N}=6$. The obtained positions of the peaks are disclosed in Table A1. The uncertainty of a given frequency $\mathrm{i}$ and a given number of gaussians $\mathrm{N}$ $\left(\Delta v_{i}(N)\right)$ has been estimated by evaluating $\left(\Delta v_{i}(N)=\left(\mid v_{i}(N+1)-\left(v_{i}(N) \mid\right)\right.\right.$. These uncertainty values are shown in Table A1 between parentheses. As can be seen in Figure A1c, Figure A2c, at least four gaussians are needed for reasonably good fitting of OPC and GEO samples. However, the inspection of the uncertainties together with the educated information gained from the simulations have made us consider that the use of five gaussians provides a sensible deconvolution over the analyzed frequency. 

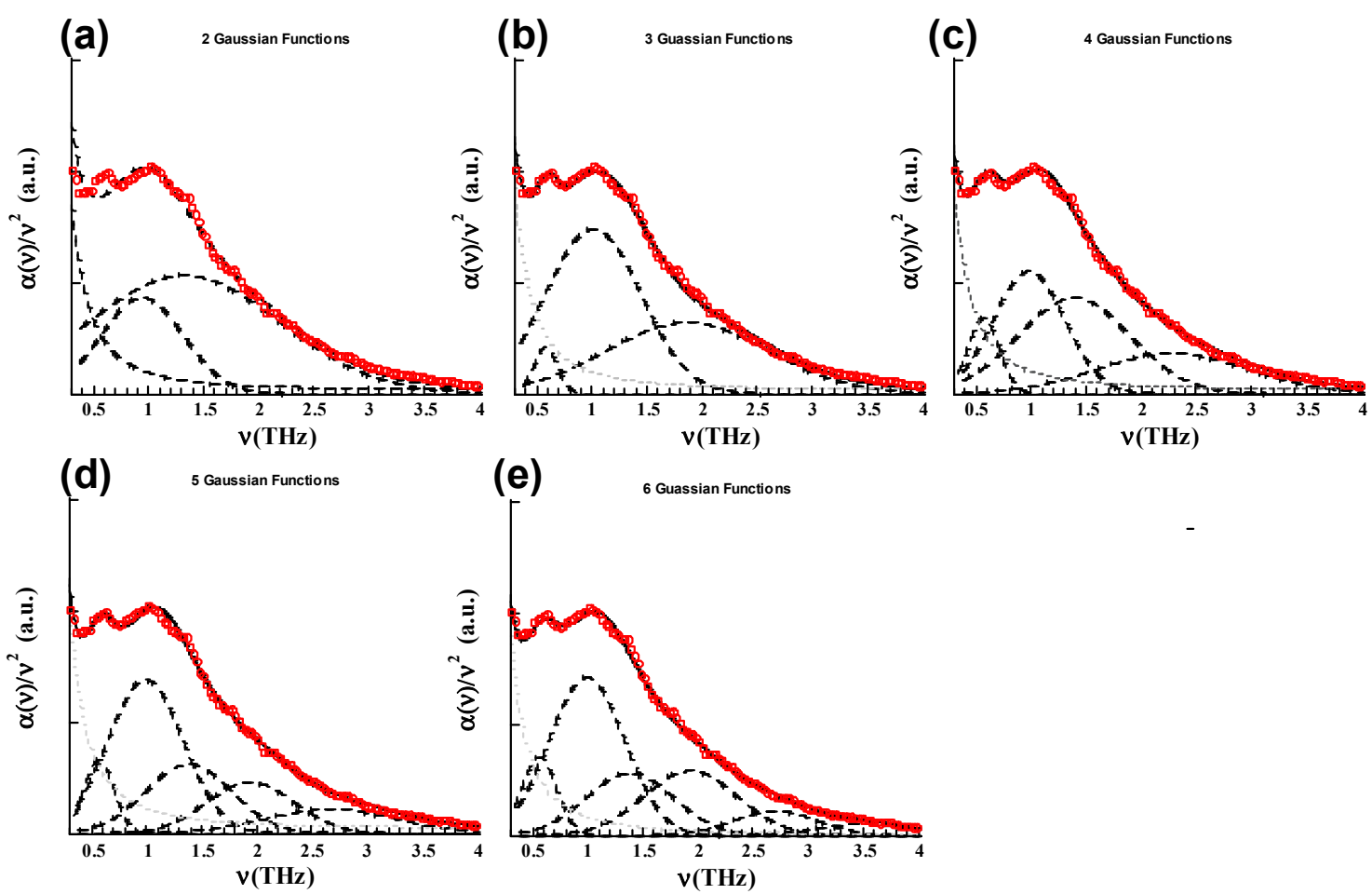

Figure A1. Deconvolution of the absorbance of OPC cement paste spectra with 2 (a), 3 (b), 4 (c), 5 (d) and 6 (e) gaussians.
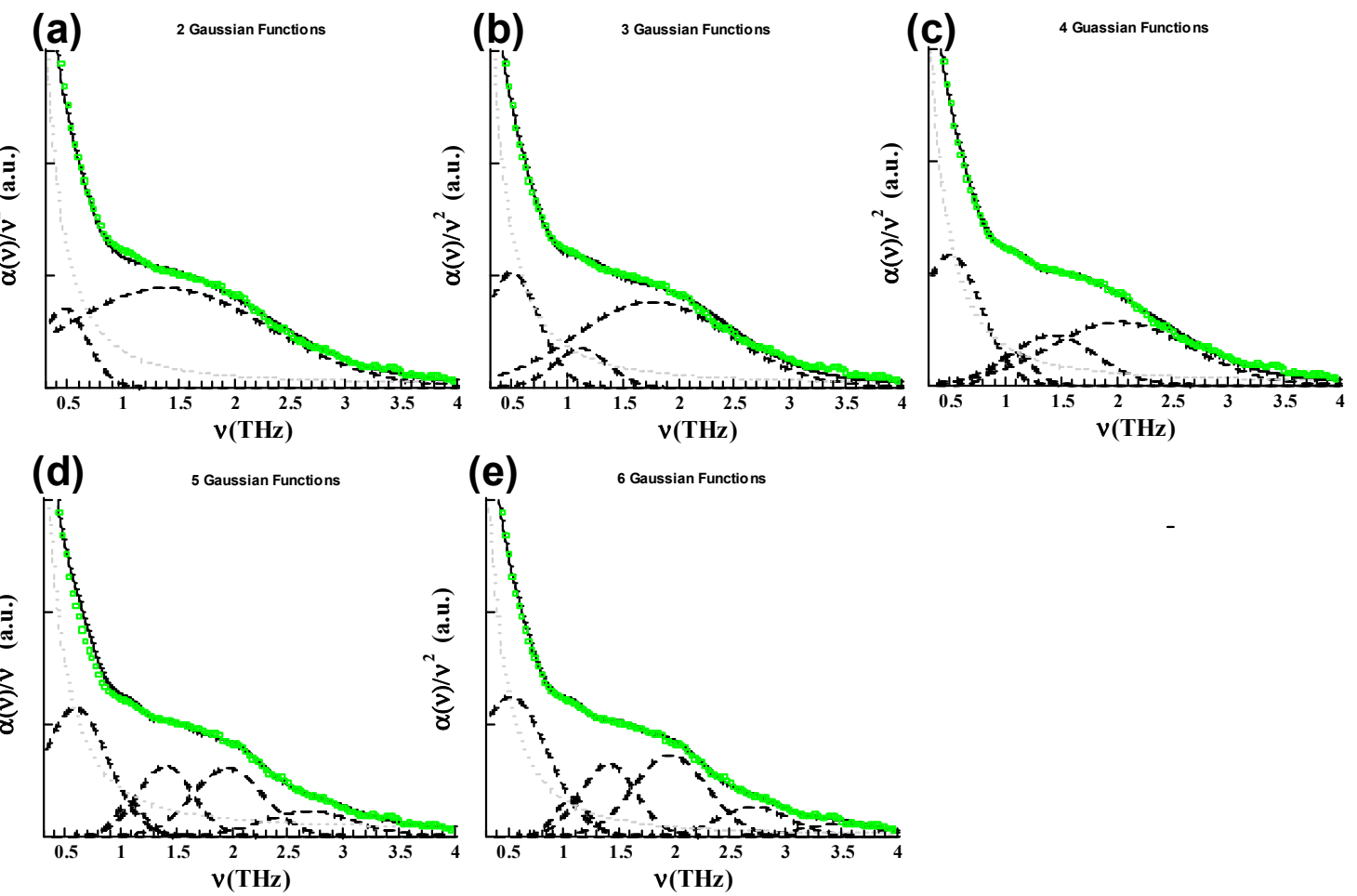

Figure A2. Deconvolution of the absorbance of GEO cement paste spectra with 2 (a), 3 (b) 4 (c), 5 (d) and 6 (e) gaussians. 
Table A1. Positions of the peaks in terms of the number $(\mathrm{N})$ of used gaussians together with the uncertainty of the positions.

\begin{tabular}{|c|c|c|c|c|c|c|}
\hline OPC spectra & $\begin{array}{c}v_{1}\left(\Delta v_{1}\right) \\
(\mathrm{THz})\end{array}$ & $\begin{array}{c}v_{2}\left(\Delta v_{2}\right) \\
(\mathrm{THz})\end{array}$ & $\begin{array}{c}v_{3}\left(\Delta v_{3}\right) \\
(\mathrm{THz})\end{array}$ & $\begin{array}{c}v_{4}\left(\Delta v_{4}\right) \\
(\mathrm{THz})\end{array}$ & $\begin{array}{c}v_{5}\left(\Delta v_{5}\right) \\
(\mathrm{THz})\end{array}$ & $\begin{array}{c}v_{6}\left(\Delta v_{6}\right) \\
(\mathrm{THz})\end{array}$ \\
\hline$N=2$ & $\begin{array}{c}0.92 \\
(0.34) \\
\end{array}$ & $\begin{array}{c}1.32 \\
(0.34) \\
\end{array}$ & & & & \\
\hline $\mathrm{N}=3$ & $\begin{array}{l}0.58 \\
(0.0)\end{array}$ & $\begin{array}{c}1.01 \\
(0.01)\end{array}$ & $\begin{array}{c}1.88 \\
(0.48)\end{array}$ & & & \\
\hline $\mathrm{N}=4$ & $\begin{array}{c}0.58 \\
(0)\end{array}$ & $\begin{array}{l}1.0 \\
(0)\end{array}$ & $\begin{array}{c}1.40 \\
(0)\end{array}$ & $\begin{array}{l}2.35 \\
(0.4)\end{array}$ & & \\
\hline $\mathrm{N}=5$ & $\begin{array}{c}0.58 \\
(0.01)\end{array}$ & $\begin{array}{c}1.00 \\
(0.01)\end{array}$ & $\begin{array}{l}1.40 \\
(0)\end{array}$ & $\begin{array}{c}1.95 \\
(0)\end{array}$ & $\begin{array}{c}2.75 \\
(0)\end{array}$ & \\
\hline$N=6$ & 0.57 & 0.99 & 1.40 & 1.95 & 2.75 & 3.65 \\
\hline GEO spectra & $\begin{array}{c}v_{1}\left(\Delta v_{1}\right) \\
(\mathrm{THz})\end{array}$ & $\begin{array}{c}v_{2}\left(\Delta v_{2}\right) \\
(\mathrm{THz})\end{array}$ & $\begin{array}{c}v_{3}\left(\Delta v_{3}\right) \\
(\mathrm{THz})\end{array}$ & $\begin{array}{c}v_{4}\left(\Delta v_{4}\right) \\
(\mathrm{THz})\end{array}$ & $\begin{array}{c}v_{5}\left(\Delta v_{5}\right) \\
(\mathrm{THz})\end{array}$ & $\begin{array}{c}v_{6}\left(\Delta v_{6}\right) \\
(\mathrm{THz})\end{array}$ \\
\hline $\mathrm{N}=2$ & $\begin{array}{c}0.45 \\
(0.04) \\
\end{array}$ & $\begin{array}{c}1.44 \\
(0.32) \\
\end{array}$ & & & & \\
\hline $\mathrm{N}=3$ & $\begin{array}{c}0.49 \\
(0.02)) \\
\end{array}$ & $\begin{array}{c}1.12 \\
(0.05)\end{array}$ & $\begin{array}{c}1.82 \\
(0.41)\end{array}$ & & & \\
\hline $\mathrm{N}=4$ & $\begin{array}{c}0.51 \\
(0.09)\end{array}$ & $\begin{array}{c}1.07 \\
(0.07)\end{array}$ & $\begin{array}{c}1.41 \\
(0.01)\end{array}$ & $\begin{array}{l}2.05 \\
(0.1)\end{array}$ & & \\
\hline $\mathrm{N}=5$ & $\begin{array}{c}0.6 \\
(0.06)\end{array}$ & $\begin{array}{c}1.0 \\
(0.05)\end{array}$ & $\begin{array}{c}1.40 \\
(0.01)\end{array}$ & $\begin{array}{c}1.95 \\
(0.05)\end{array}$ & $\begin{array}{c}2.75 \\
(0.02)\end{array}$ & \\
\hline$N=6$ & 0.54 & 1.05 & 1.41 & 2.0 & 2.73 & 3.53 \\
\hline
\end{tabular}

\section{References}

1. Tonouch, M. Cutting-edge Terahertz technology. Nat. Photonics 2007, 1, 97-105. [CrossRef]

2. Martin-Moreno, L.; Garcia-Vidal, F.J.; Lezec, H.J.; Pellerin, K.M.; Thio, T.; Pendry, J.B.; Ebbesen, T.W. Theory of Extraordinary Optical Transmission through Subwavelength Hole Arrays. Phys. Rev. Lett. 2001, 86, 1114-1117. [CrossRef]

3. Ebbesen, T.W.; Lezec, H.J.; Ghaemi, H.; Thio, T.; Wolf, P.A. Extraordinay optical transmission through subwavelength hole mays. Nature 1998, 391, 667-669. [CrossRef]

4. Krishnamoorthy, H.N.S.; Adamo, G.; Yin, J.; Savinov, V.; Zheludev, N.I.; Soci, C. Infrared dielectric metamaterials from high refractive index chalcogenides. Nat. Commun. 2020, 11, 169. [CrossRef]

5. Liu, X.; Chang, Q.; Yan, M.; Wang, X.; Zhang, H.; Zhou, H.; Fan, T. Scalable spectrally selective mid-infrared meta-absorbers for advanced radiative thermal engineering. Phys. Chem. Chem. Phys. 2020, 22, 13965-13974. [CrossRef]

6. Beruete, M.; Sorolla, M.; Campillo, I.; Dolado, J.S.; Martin-Moreno, L.; Bravo-Abad, J.; Garcia-Vidal, F.J. Enhanced millimeter-wave transmission through subwavelength hole arrays. Opt. Lett. 2004, 29, 2500-2502. [CrossRef] [PubMed]

7. Beruete, M.; Sorolla, M.; Campillo, I.; Dolado, J.S.; Martín-Moreno, L.; Bravo-Abad, J.; García-Vidal, F.J. Enhanced Millimeter Wave Transmission Through Quasioptical Subwavelength Perforated Plates. IEEE Trans. Antennas Propag. 2005, 53, 1897-1903. [CrossRef]

8. Beruete, M.; Campillo, I.; Dolado, J.S.; Rodriguez-Seco, J.E.; Perea, E.; Falcone, F.; Sorolla, M. Very low profile and dielectric loaded feeder antenna. IEEE Antennas Wirel. Propag. Lett. 2007, 6, 544-548. [CrossRef]

9. Beruete, M.; Campillo, I.; Dolado, J.S.; Rodriguez-Seco, J.E.; Perea, E.; Falcone, F.; Sorolla, M. Low-profile corrugated feeder antenna. IEEE Antennas Wirel. Propag. Lett. 2005, 4, 378-380. [CrossRef]

10. Ramachandran, V.S.; Beaudoin, J.J. Handbook of Analytical Techniques in Concrete Science and Technology: Principles, Techniques and Applications; Elsevier: Amsterdam, The Netherlands, 2000. 
11. Cong, X.; Kirkpatrick, R.J. 29Si MAS NMR Study of the Structure of Calcium Silicate Hydrate. Adv. Cement Based Mater. 1996, 3, 144-146. [CrossRef]

12. Brough, A.R.; Dobson, C.M.; Richardson, I.G.; Groves, G.W. In Situ Solid State NMR Studies of Ca3SiO5: Hydration at Room Temperature and at Elevated Temperatures Using 29Si Enrichment. J. Mater. Sci. 1994, 29, 3926-3940. [CrossRef]

13. Palomo, A.; Grutzeck, M.W.; Blanco, M. Alkali-activated fly ashes-A cement for the future. Cem. Concr. Res. 1999, 29, 1323-1329. [CrossRef]

14. Duxson, P.; Fernández-Jiménez, A.; Provis, J.L.; Lukey, G.C.; Palomo, A.; van Deventer, J.S.J. Geopolymer technology: The current state of the art. J. Mater. Sci. 2007, 42, 2917-2933. [CrossRef]

15. Provis, J.L.; Lukey, G.C.; van Deventer, J.S.J. Do Geopolymers Actually Contain Nanocrystalline Zeolites? A Reexamination of Existing Results. Chem. Mater. 2005, 17, 3075-3085. [CrossRef]

16. Pellenq, R.J.-M.; Kushima, A.; Shahsavari, R.; Van Vliet, K.J.; Buehler, M.J.; Yip, S.; Ulm, F.J. A realistic moleculart model of cement hydrates. Proc. Natl. Acad. Sci. USA 2009, 106, 16102-16107. [CrossRef] [PubMed]

17. Dolado, J.S.; Griebel, M.; Hamaekers, J.; Heber, F. The nano-branched structure of cementitious calcium-silicate-hydrate gel. J. Mater. Chem. 2011, 21, 4445-4449. [CrossRef]

18. Manzano, H.; Dolado, J.; Ayuela, A. Elastic Properties of the Main Species Present in Portland Cement Pastes. Acta Mater. 2009, 57, 1666-1674. [CrossRef]

19. Qomi, M.J.A.; Krakowiak, K.J.; Bauchy, M.; Stewart, K.L.; Shahsavari, R.; Jagannathan, D.; Brommer, D.B.; Baronnet, A.; Buehler, M.J.; Yip, S.; et al. Combinatorial Molecular Optimization of Cement Hydrates. Nat. Commun. 2014, 5, 1-10. [CrossRef]

20. Lolli, F.; Manzano, H.; Provis, J.L.; Bignozzi, M.C.; Masoero, E. Atomistic simulations of geopolymer models: The impact of disorder on structure and mechanics. Appl. Mater. Interfaces 2018, 25, 22809-22820. [CrossRef]

21. Richet, N.F.; Kawaji, H.; Rouxel, T. The boson peak of silicate glasses: The role of Si-O, Al-O, and Si-N bonds. J. Chem. Phys. 2010, 133, 044510. [CrossRef]

22. Baggioli, M.; Zaccone, A. Universal Origin of Boson Peak Vibrational Anomalies in Ordered Crystals and in Amorphous Materials. Phys. Rev. Lett. 2019, 2019 122, 145501. [CrossRef]

23. Grigera, T.S.; Martin-Mayo, V.; Parisi, G.; Verrocchio, P. Phonon interpretation of the 'bosonpeak' in supercooled liquids. Nature 2003, 422, 289-292. [CrossRef] [PubMed]

24. Qomi, M.J.A.; Ulm, F.-J.; Pellenq, R.J.-M. Physical Origins of Thermal Properties of Cement Paste. Phys. Rev. Appl. 2015, 3, 064010. [CrossRef]

25. Lunkenheimer, P.; Emmert, S.; Gulich, R.; Köhler, M.; Wolf, M.; Schwab, M.; Loid, A. Electromagnetic-radiation absorption by water. Phys. Rev. E 2017, 96, 062607. [CrossRef] [PubMed]

26. Cerveny, S.; Arrese-Igor, S.; Dolado, J.S.; Gaitero, J.J.; Alegría, A.; Colmenero, J. Effect of hydration on the dielectric properties of C-S-H gel. J. Chem. Phys. 2011, 134, 034509. [CrossRef] [PubMed]

27. Monasterio, M.; Jansson, H.; Gaitero, J.J.; Dolado, J.S.; Cerveny, S. Cause of the fragile-to-strong transition observed in water confined in C-S-H gel. J. Chem. Phys. 2013, 139, 164714. [CrossRef]

28. Goracci, G.; Monasterio, M.; Jansson, H.; Cerveny, S. Dynamics of nano-confined water in Portland cement-Comparison with synthetic C-S-H gel and other silicate materials. Sci. Rep. 2017, 7, 1-10. [CrossRef]

29. Goracci, G.; Dolado, J.S. Elucidation of Conduction Mechanism in Graphene Nanoplatelets (GNPs)/Cement Composite Using Dielectric Spectroscopy. Materials 2020, 13, 275. [CrossRef]

30. Senftle, T.P.; Hong, S.; Islam, M.M.; Kylasa, S.B.; Zheng, Y.; Shin, Y.K.; Junkermeier, C.; Engel-Herbert, R.; Janik, M.J.; Aktulga, H.M.; et al. The ReaxFF Reactive Force-Field: Development, Applications and Future Directions. NPJ Comput. Mater. 2016, 2, 15011. [CrossRef]

31. Duque, E. Atomistic Simulations of Confined Species in 2D Nanostructures: Clays and C-S-H Gel. Ph.D. Thesis, Basque Country University, Leioa, Spain, 2018.

32. Hassan, I.; Antao, S.M.; Parise, J.B. Sodalite: High-temperature structures obtained from synchrotron radiation and Rietveld refinements. Am. Mineral. 2004, 89, 359-364. [CrossRef]

33. Sanders, M.J.; Leslie, M.; Catlow, C.R.A. Interatomic potentials for $\mathrm{SiO}_{2}$. J. Chem. Soc. Chem. Commun. 1984, 1271-1273. [CrossRef]

34. Gale, J.D. GULP-a computer program for the symmetry adapted simulation of solids. J. Chem. Soc. Faraday Trans. 1997, 93, 629-637. [CrossRef] 
35. Kumar, P.; Wikfeldt, K.T.; Schlesinger, D.; Pettersson, L.G.M.; Stanley, H.E. The Boson peak in superccoled water. Sci. Rep. 2013, 3, 1980. [CrossRef] [PubMed]

36. Woods, K.N. The glassy state of crambin and the THz time scale protein-solvent fluctuations possibly related to protein function. BMC Biophys. 2014, 7, 8. [CrossRef] [PubMed]

37. Mallamace, F.; Corsaro, C.; Mallamace, D.; Chen, S.; Fratini, E.; Baglioni, P. The Boson peak interpretation and evolution in confined amorphous water. Sci. China Phys. Mech. Astron. 2019, 62, 107004. [CrossRef]

38. Woods, K.N. Solvent-induced backbone fluctuations and the collective librational dynamics of lysozyme studied by THz spectroscopy. Phys. Rev. E 2010, 81, 031915. [CrossRef]

39. Martauz, P.; Janotka, I.; Strigáč, J.; Bačuvčík, M. Fundamental properties of industrial hybrid cement: Utilization in ready-mixed concretes and shrinkage-reducing applications. Mater. Construcción 2016, 66, 322. [CrossRef]

(C) 2020 by the authors. Licensee MDPI, Basel, Switzerland. This article is an open access article distributed under the terms and conditions of the Creative Commons Attribution (CC BY) license (http://creativecommons.org/licenses/by/4.0/). 